\title{
Embedded knowledge and offshore software development
}

\author{
Brian Nicholson ${ }^{\mathrm{a}, *}$, Sundeep Sahay ${ }^{\mathrm{b}}$ \\ a School of Accounting and Finance, University of Manchester, Mezzanine Floor, Crawford House, \\ Booth Street East, Manchester M13 9PL, UK \\ b Institute of Informatics, University of Oslo, Oslo, Norway
}

\begin{abstract}
Offshore software development scenarios may include groups with domain specific knowledge who collaborate internationally across multiple local contexts. A key challenge in the understanding and also practice of such distributed work is concerned with the issue of knowledge, and how it can be effectively managed. In this paper, we develop a conceptual scheme based on theories associated with embedded knowledge. Drawing on evidence from a longitudinal case study of a British software company with an offshore subsidiary in India, we discuss problems associated with the embeddedness of knowledge in two geographically separated units of a firm.

(C) 2004 Elsevier Ltd. All rights reserved.
\end{abstract}

Keywords: Knowledge management; Case study; Software development

\section{Introduction}

Software development has been described as a complex problem solving process simultaneously involving a number of individuals, teams, and organisations with competing goals, interests, and responsibilities (Curtis, Kransner, \& Iscoe, 1988). Designers and developers are involved in designing and writing the program, project managers are responsible for the successful completion of the project, and the endusers provide the test of whether the software is acceptable to them or not. These

\footnotetext{
${ }^{*}$ Corresponding author. Tel.: +44-161-275-4024; fax: +44-161-275-4023.

E-mail address: brian.nicholson@man.ac.uk (B. Nicholson), sundeep@ifi.uio.no (S. Sahay).
} 
different groups both provide and require varying forms of knowledge and expertise at different stages of the project. Waterson, Clegg, and Axtell (1997) emphasise that software development involves a variety of cognitive and organisational issues concerning the communication and co-ordination of knowledge relating to the program, the methodologies to be used, the domain area and various organisational practices such as reporting relationships within the project team. Managing these processes by which knowledge is acquired, shared, and integrated between these various individuals, teams and organisations is a crucial task in the process of software development (Walz, Elam, \& Curtis, 1993).

Software development represents "knowledge intensive" work that requires organisations to increasingly depend on "knowledge workers" who draw upon their cognitive abilities and their specialist resources (Blackler, 1995). However, individual team members do not have all the knowledge required for the project and they need to acquire additional information and knowledge from different sources such as relevant documentation, formal training sessions, results of trial and error exercises and other team members (Walz et al., 1993). The process of knowledge acquisition and sharing is problematic as knowledge is embedded at societal, organization, and cognitive levels of analysis (Lam, 1997). In recent years, an increasing focus is being placed on understanding the nature of embedded knowledge and the challenges inherent in trying to acquire share and use such knowledge (Lam, 1997, 2000; Sole \& Edmondson, 2002).

Several authors have emphasised how routines and standard operating procedures are used to transfer knowledge (Cohen \& Bacdayan, 1994; Huber, 1991; Levitt \& March, 1988). Some of this knowledge is embedded in local contexts with the implication that migration across boundaries is problematic (Bechky 2003; Lam, 1997, 2000; Szulanski, 1996; von Hippel, 2001). Badaracco (1991): p. 79 distinguishes between migratory and embedded knowledge. While migratory knowledge resides in "mobile packages" such as books, formulas and machines, embedded knowledge tends to be non-migratory and "resides primarily in specialised relationships among individuals and groups and in the particular norms, attitudes, information flows and ways of making decisions that shape their dealings with each other". Thus, knowledge residing in organising principles, routines and standard operating procedures may be non-migratory due to embeddedness of knowledge in context.

The increasing research interest in the context dependency of knowledge has evolved alongside critiques from various authors (for example Bechky, 2003; Hislop, 2002; Mc Dermott, 1999; Sole \& Edmondson, 2002; Walsham, 2001b) of the treatment of knowledge as an "explicit" commodity, implying that with sufficient effort, catalyzed by the capabilities of information and communication technology (ICT), tacit knowledge can be made explicit and transferred relatively freely across the globe (for example Nonaka \& Takeuchi, 1994). By contrast, the embedded perspective on organisations provides a framework for examining the embeddedness of knowledge in context (Dacin, Mark, Ventresca, \& Beal, 1999; Granovetter, 1985; Lam, 1997, 2000) and how problems associated with it may be overcome. This perspective is pertinent because the nature and structure of offshore projects typically requires the task of software development to be split into smaller modules, which are 
then executed by organisations or groups that are based in different countries. These different components of the development activity need to be continuously monitored, co-ordinated and then subsequently integrated into a product that is acceptable to end-users. Cockburn (2002): p. 81 argues that distributed development is inherently ineffective since "project costs increase in proportion to the time it takes for people to understand each other". For Cockburn, the time taken for effective understanding to develop is related to the proximity of the people involved. An opposing view (for example, Carmel, 1999) argues for the positive possibilities of software development to take place in dispersed teams where projects can "follow the sun." The argument is vindicated by the fact that an increasing number of organisations are adopting offshore development as a preferred strategy to meet their software development needs (Sahay, Nicholson, \& Krishna, 2003). Carmel argues for the power of ICT to transcend the limitations of time and space differences in software development, whereas others (for example Brown, 1998; Hislop, 2002) argue that a reliance on ICT as a means of transferring knowledge is insufficient. For the latter perspective, knowledge should be viewed in relation to the institutional arrangements within which it is created and used (Robertson, Swan, \& Scarborough, 2000). These alternative viewpoints raise two interesting research questions, which are the focus of this paper:

- What is the nature of embedded knowledge in offshore development?

- How do individuals, teams, and organisations manage this complex problem of embedded knowledge in offshore development?

The aim of this paper is to explore these questions through an empirical examination of an offshore development relationship between a British firm "Sierra" (a pseudonym) and its Indian subsidiary. The rest of the paper is organised as follows. In the next section, we theoretically develop the concept of embedded knowledge and how it relates to software development more generally, and in offshore settings more specifically. In Section 3, we present the research approach followed by the case study description in Section 4. Section 5 contains the analysis and finally in Section 6 we develop some theoretical and practical implications around the issue of embedded knowledge in offshore settings.

\section{Embedded knowledge and software development}

The theory of embeddedness conceptualises social action as being situated within broader institutional and political frameworks. Dacin et al. (1999) argues that the proponents of embeddedness such as Granovetter (1985) in transaction economics and Zukin and DiMaggio (1990) in political science present a contextually rooted perspective on economic activity that is conceptually richer than the antithetical "social vacuum" perspective typically implied in neo-classical economics. Embeddedness research has been able to establish that economic and organisational activities are embedded within larger and more complex social processes that shape and are shaped by human activity. 
Recent work in organisation studies has drawn upon and expanded the traditional conception of embeddedness as used in economics and market transactions and applied it to understand the workings of particular domain areas. Uzzi (1996), for instance, analyses the structural embeddedness of inter-organisational networks in multiple cases of apparel manufacturing. Uzzi's focus was at the level of closeness of the relationships, the intensity of information exchange and the extent to which resources are adapted. In another influential study, Lam (1997) has drawn upon similar ideas to analyse the knowledge related challenges in managing a cross-cultural (Britain-Japan) technology development project.

Prior research in information systems directs attention to the important role of context in shaping software development processes. Although these studies do not explicitly draw on concepts of embeddedness, they are concerned with similar issues. For example, Walsham (2002) analyses the influence of culture on software development, Waterson et al. (1997) and Walz et al. (1993) emphasise cognitive and organisational issues. The practice based learning perspective (Brown \& Duguid, 1991; Lave \& Wenger, 1991) focuses on the situated nature of knowledge that is embedded in work practices of particular organisational sites and its implications on sharing in collocated settings (Hayes \& Walsham, 2001; Sole \& Edmondson, 2002).

Similar contextual analysis of software development in cross-cultural settings remain far more limited. Lam's studies (1997, 2000), although not explicitly analysing the process of software development are an exception. This research is of particular interest because it theorises how knowledge in intra and inter-firm settings is embedded within a firm's co-ordination mechanisms and organisational routines, which in turn are significantly shaped by broader societal institutions. Lam's case concerns a collaborative project between a British and Japanese firm. The Japanese approach to design relied on experimentation, intensive collocated interaction and learning by doing. This made it difficult for them to formally codify their ideas in a manner that was considered logical and consistent by the British who were used to a formalised and documented high-level design language. The varying forms of knowledge embeddedness made the transfer of knowledge between the two firms problematic and led to problems in the management of the project.

In a subsequent paper, Lam (2000) further extended these ideas by describing how the sources of embeddedness of knowledge may be understood at three analytical levels of cognitive, organisational and societal, and their interconnections. At the cognitive level, sources of embeddedness concern the tacit nature of human knowledge related to skills, techniques, know how and routines that cannot be easily articulated or explicitly codified (Polanyi, 1962, 1966). Such tacit knowledge finds its application in practical settings, best developed in conditions of proximity where the learner watches the expert to mentally establish how things work.

The organisational level focuses on the organising principles of the firm, including its structures of co-ordination, the behavioural routines and work related roles and responsibilities of organisational actors. Sources of embeddedness of knowledge include, for example, the structure of co-ordination, which determines the organisation's capability to mobilise and integrate different types of knowledge and shape the relationship between individual and collective learning. Brown (1998) points to 
how actual informal practices may differ from the formal way an organisation describes structures of co-ordination in manuals and training programs. Drawing on Orr's (1990) study of Xerox photocopy technicians, Brown identifies the situated understanding of the photocopier machine which the technicians shared informally through "war stories" of successful repairs involving improvisations. For Brown, the role of ICT therefore is to support the effort of getting the formal organisation and the informal, local one to work together.

Sources of embeddedness at the societal level draw attention to how broader societal institutions, such as relating to labour markets and universities, shape organisational routines, co-ordination rules and the knowledge base of the firm (Lam, 2000: p. 488). Education and training shape the social constitution of knowledge and thus provide the basis of qualification, work status and job boundaries. A similar contextual analysis by Sahay and Walsham (1997) related the weak use of maps in the Indian Forestry Department to broader societal tendencies. People rarely used maps in every day life such as for travel, preferring instead to ask directions from people on the roads.

The three analytical levels of cognitive, organisational and societal are interconnected and nested in each other, both shaping and being shaped by collective as well as through individual action (Dacin et al., 1999). For example, Lam (1997) argues that the cognitive knowledge of the Japanese and British engineers was nested in different engineering qualification systems at a societal level, and "professional" versus "organisational" models at the firm level. While British employers tried to buy readily available specialists from the market, the Japanese preferred to develop their own technical staff through on the job training. The Japanese engineering education is oriented to developing broad practical engineering skills as opposed to the early specialisation and engineering science orientation in Britain. This nestedness at the societal and firm levels helped to shape cognitive level processes. While the Japanese placed more reliance on tacit knowledge and practical know how nested in social networks, the British attempted to make tacit knowledge explicit by standardised documentation guided by their formal training and specialist expertise.

The above arguments around the embeddedness of knowledge has implications for our analysis of the nature of challenges in software development more generally and in offshore settings more specifically. We discuss these issues in the following two sections.

\subsection{Embedded knowledge in software development}

Embeddedness of knowledge in software development has been emphasised by various authors. Telioglu and Wagner (1999), for example, discuss how knowledge in software development is constituted and expressed in various products (such as processes and programming tools), processes (such as software development and project management methodologies), and practices (such as norms of communication) and notations (such as use of flow charts). This research emphasises embeddedness of knowledge at the cognitive level. For Telioglu and Wagner, software 
development is a situated activity that takes place in specific locations by people who act from their specific context of knowledge, tools, tasks, colleagues, idiosyncrasies, organisational memory and history. Walz et al. (1993) similarly describe a case where a software development team's "informal memory" consisted of notes scrawled by individuals in margins of documents and the blackboard rather than in documentation as specified by formal software development and quality methodologies.

At the organisational level, software developers rely on architecture, plans and processes to establish effective co-ordination among team members (Herbsleb \& Grinter, 1999). An extreme form of this organisational structuring is the Japanese software factory and its emphasis on principles to achieve efficiencies of scale (Cusumano, 1991). In practice, this ideal as imagined in the software factory is seldom fully attained because challenges arise such as the departure of key personnel. This may be due to labour market fluctuations where demand exceeds supply that must be accommodated and dealt with in an improvised manner (Herbsleb \& Grinter, 1999). Despite the claim to be following formal organisational routines, developers tend to heavily rely on informal, ad hoc communication and improvisations to fill in on the details, handle exceptions, correct mistakes and the effects (Kraut \& Streeter, 1995). Nandhakumar (2002) describes how the frequent problem of "late delivery" in software projects relates to the mismatch between what organisations say they are doing and what happens in practice. Typically, software development projects are described to be organised as an orderly, discrete, and regular sequence, with the help of time management techniques to optimise schedules and monitor progress. However, the practice of software projects is quite different, as people have different temporal rhythms, and involved in multiple activities simultaneously with competing demands on time. Knowledge of these temporal rhythms embedded within the existing everyday routines and pressures of individuals and groups are typically not taken into account by formalised organisational project management routines.

There is empirical evidence of sources of embeddedness of knowledge at the societal level influencing software development projects. Walsham and Sahay (1999) describe the design, development and implementation of GIS applications for land management in India. They describe how Indian society is not a "map-based culture" in contrast to practice in many Western countries where maps are used extensively in everyday life, for example while travelling. The users, the district-level foresters, were described to have weak cognitive frames around maps arising from their lack of prior experience and were as a result reluctant to use GIS maps. This lack of map usage was inscribed in organisational routines such as the annual deforestation statistics being computed by foresters physically inspecting tree loss rather than using remotely sensed maps. This example, in addition to illustrating the societal level of knowledge embeddedness, also shows how the organisational routine of reporting deforestation and cognitive individual dispositions to use maps are all nested and interconnected in and with each other. Understanding this nestedness is crucial to our analysis of software development projects generally, and offshore development projects, which we discuss below. 


\subsection{Embedded knowledge in offshore software development}

Offshore software development is different from co-located development for three reasons: the diversity of organisations and cultures co-involved in the development process; the nature of work; and the processual nature of the offshore relationship. These characteristics contribute to the challenge of embeddedness of knowledge. These issues are discussed with some pertinent examples to highlight this challenge.

Diversity of organisations and cultures: Embeddedness of knowledge has particular relevance in the context of offshore software development as it involves people from different organisations and countries with different languages and work practices working together in the process of software development (Jarvenpaa \& Leidner, 1999). Prior research drawing on theories of culture argues that national societies reflect different assumptions for example related to time which influences social action. Krishna and Sahay (2001) discuss a case study of software development between India and Japan. The Japanese took much longer time to reply to an email as compared to the Indians and this had particular implications. Perceived delays by the Indian side were attributed to the Japanese having problems with English language and their insistence on detail and completeness in reply. However, the Japanese would not send the reply until all the points raised in the email they received were addressed. Secondly, the Japanese tended to prefer verbal to written communication. Thirdly, issues in the Japanese firm were usually resolved face-to-face rather than by writing memos. In contrast, the Indian engineers found the Japanese "silence" disconcerting and interpreted it to reflect the onset of a problem. The Japanese did not see the time delay as a problem. This illustrates how lack of understanding of the embeddedness of knowledge of local conceptions of time in Japan and India led to problems with individual processes of communication and project delays.

Geographical, temporal and cultural separation influences the development of mutual knowledge, often causing serious misunderstandings in software development projects (Cramton, 2001; Robey, Khoo, \& Powers, 2000). Tsoukas (1996) points out that articulated knowledge is based on an unarticulated background of what is being taken for granted that is tacitly integrated by individuals, residing in social practices, forms of life into which one happens to participate. The lack of a common institutional background causes misunderstandings and breakdowns. For example, a Mumbai based software firm was contracted to develop software for the British social security benefit. In India, the concept of a State supported welfare system does not exist. Therefore the Indian programmers found it hard to conceptualise how and why a government would provide payment to the unemployed. The Indian staff working on the development had never lived or worked in England and took considerably longer than people there to understand and interpret user requirements. Many of the England-based contractors had made unemployment claims at some stage and understood the language and terminology and consequently took less time to design and develop the functionality of this system (Nicholson, 1999). These findings concur with Robey et al. where geographical and temporal separation also threatened the process of situated practice because 
members were not co-located and thus unable to share locale or site-specific practices and knowledge.

Nature of work: Offshore software work covers a wide spectrum of activities ranging from relatively specialised technical work involving algorithms, web development, interface design and coding to lower-level technical work of customer support call centres and data entry. These different kinds of work place varying demands on knowledge and skill levels. For example, while call centre work primarily requires English language and typing skills, software design projects require knowledge of business processes, design methodologies and development tools. In the early stages of the Indian software industry, activities that were sourced offshore tended to involve structured maintenance and testing work that required a limited degree of contextual knowledge (Apte, 1990). Analysis and design tasks, which in contrast require more detailed knowledge of the user site and business processes came later and were typically completed in the user country. McFarlan (1995) suggested that highly structured tasks are most suitable for offshore outsourcing, and more unstructured tasks should not be undertaken offshore. However, many Indian firms such as Mastek undertake up to $70 \%$ of their projects including some unstructured work in India (Nicholson, 1999).

To deal with the diversity of work, firms have tried to maximise efficiencies through the strategy of developing various organisational and inter-organisational standards around physical artefacts, technical platforms and management processes (Sahay, 2003). Designing and implementing these standards involves taking into consideration multiple levels of context. For example, reward and recognition schemes require knowledge of societal and industry norms of compensation, organisational human resources practices, and the implications of these schemes on individual identities. Appropriate reward schemes in India need to be developed in harmony with the societal norms that value an individual going abroad for work. Organisational practices must reflect the importance of praise from superiors and take into account the quest of individual developers to further enhance their technical skills to become more marketable globally (Sahay et al., 2003).

The processual nature of the offshore relationship: Unlike virtual teams that are typically short term in nature and disbanded once a project is completed (Sarker \& Sahay, 2003), offshore outsourcing relationships are longer-term and require significant investments from both sides. This might include for example language training and establishing dedicated telecommunication links. These relationships involve a longer-term process including phases of initiation, growth and maturity with varying knowledge demands on organisations and individuals at different stages. In the early stages it may be enough to possess knowledge about the technical tools, platforms and related artefacts. With growth and maturity, there are additional demands to gain knowledge about management practices and processes, such as reporting and budgeting standards. A crucial task in the growth stage is to manage the knowledge that exists onsite at the customer site and offshore at the development site. This is performed by keeping the appropriate number of people with the desired knowledge skills at the two locations and establishing mechanisms for their communication and co-ordination. This onsite - offshore knowledge mix is 
not static, and varies with the workload demands on knowledge, the level of shared understanding between groups, and future knowledge demands, for example the kind of projects to be undertaken.

In summary, the three characteristics discussed above raise particular challenges for understanding the nature and implications of embedded knowledge on software development. Focusing on understanding sources of embeddedness and the implications is fundamental to analyse the workings of such relationships. Our theoretical framework (summarised in Table 1) is based on the idea that knowledge in offshore software development is nested in interconnected cognitive, organization and societal levels of analysis. Diverse forms of knowledge need to be taken into consideration, which are both formal and documented and informal and local. The processual nature of the relationship implies that knowledge demands are constantly changing with the stages of the relationship and the kind of projects being undertaken. The high rates of attrition of people in the software industry raise unique demands on firms to retain and manage knowledge that is held by key people. The rapidly changing technological and market conditions raise further demands on both organisations and individuals with respect to acquiring and mastering new forms of both technical and market related knowledge. Such a holistic perspective helps to specifically understand the problem of embedded knowledge in offshore development and how organisations and individuals attempt to deal with it. We address these issues through the empirical analysis of the relationship of Sierra, England, with its subsidiary in India.

Table 1

Embeddedness of knowledge in offshore software development

\begin{tabular}{|c|c|c|}
\hline \multirow[t]{2}{*}{$\begin{array}{l}\text { Areas of } \\
\text { concern }\end{array}$} & \multicolumn{2}{|c|}{$\begin{array}{l}\text { Knowledge may be codified into "organising principles" comprising of structures and } \\
\text { processes, routines and standard operating procedures. Organisational principles which } \\
\text { can be used to mobilise knowledge in one location may be difficult to apply in another } \\
\text { context because of different individual, organisational and societal conditions } \\
\text { Sources of embeddedness of knowledge are mechanisms analysable at cognitive, } \\
\text { organisational and societal levels that contextualise knowledge } \\
\text { Sources of embeddedness may influence the migration of organising principles from one } \\
\text { location to another }\end{array}$} \\
\hline & edge & ס. \\
\hline Cognitive & $\begin{array}{l}\text { ations and frameworks } \\
\text { ape individuals sense } \\
\text { d. Tacit knowledge }\end{array}$ & $\begin{array}{l}\text { Frameworks of meaning are nested within } \\
\text { organisational and societal analytical levels }\end{array}$ \\
\hline Organ & $\begin{array}{l}\text { Specialised relationships among individuals } \\
\text { and groups and in the particular norms, } \\
\text { attitudes, information flows and ways of } \\
\text { making decisions that shape their dealings } \\
\text { with each other }\end{array}$ & $\begin{array}{l}\text { Structures of co-ordination are nested in } \\
\text { societal institutions and shape the rela- } \\
\text { tionship between individual and collective } \\
\text { learning }\end{array}$ \\
\hline Societal & $\begin{array}{l}\text { Broader societal institutions and structures } \\
\text { such as education and labour markets }\end{array}$ & $\begin{array}{l}\text { Societal institutions and structures shape } \\
\text { the legitimacy of knowledge residing in } \\
\text { organisational principles }\end{array}$ \\
\hline
\end{tabular}




\section{Research approach}

The research approach followed a longitudinal and interpretive case study methodology (Walsham, 1995; Walsham \& Sahay, 1999) conducted during 19982000. An interpretive approach assumes that the knowledge of reality is gained only through social constructions such as the use of language, attitudes and shared meanings of actors, structure and form of documents, and the use of tools, technologies and other artefacts (Klein \& Myers, 1999). Interpretive research does not predefine independent and dependent variables and determine causal relationships between them. Instead, the aim is to understand the complexity of human sense making processes, and the processes by which inter-subjectivity is obtained as the situation is constantly changing. An implication of this interpretive perspective in our research was that our aim was not to try to correlate the problems of knowledge with the success or failure of a global software development relationship. Instead, the aim was to provide insights into the processes contributing to the complexity of embedded knowledge in offshore software development settings, and the contextual conditions that contribute to this complexity.

Longitudinal designs are appropriate in the study of processes around instability and change (Vitalari, 1985). We adopted such a design as our aim was to understand issues around the nature of embedded knowledge, its management and consequences, and how these changed over time. At the start of the relationship, our focus was on trying to understand how the England-based managers had tried to establish the feasibility of doing business in India. For example, we asked questions related to the availability of knowledge workers, and the expectations Sierra had about future business growth. Subsequently, we revisited them at different points of time to see how their expectations had been met, what new future challenges and opportunities were perceived, and the strategies developed to deal with these perceptions. The longitudinal design involved firstly meeting some key respondents on both sides of the relationship at periodic intervals. We asked them to identify key events that occurred in the intervening period and the subjective understandings of the respondents around these events.

A vast amount of process data were gathered as a result of the interviews, participant observations and the reading of various documents. Langley (1999): p. 691 describes two broad strategies of analysing and theorising from process data. The first concerns the "formulation of a priori process theories and testing them using coarse-grained longitudinal time series and event history methods". Researchers adopting the second strategy choose to "plunge deeply into the processes themselves, collecting fine grained qualitative data - often, but not always, in real time - and attempting to extract theory from the ground up" (p. 691). Our research strategy broadly resonates with the second approach. We started the research with the aim of understanding how the processes of offshore software development relationships evolve over time. Through the empirical analysis we started to understand the problem of embedded knowledge in shaping the relationship. This led us to explore relevant literature in the area of knowledge and knowledge management, especially in the context of distributed settings. The evolutionary process of conducting field 
work, reading relevant theoretical work and discussions with colleagues, led to the articulation of the conceptual framework of embedded knowledge that is presented in this paper.

The study of the relationship started in 1998, even though the offshore activities of Sierra, the England-based firm under study, had started in India in 1996. Events prior to 1998 were historically reconstructed. In 1998, Sierra England decided to set up its subsidiary operations in Bangalore, India. Since then, we followed the relationship over time until 2000 when the decision was made to shut down the subsidiary operations. We met participants in India and head office in England at regular time intervals in order to gain insights into the nature of the relationship, how it was evolving, and how the unfolding events compared to respondents' earlier expectations. The interviews conducted were largely dictated by the conditions of availability of Sierra staff given that they were extremely busy and were frequently travelling. However, we did make it a point to meet the India centre management in each of the three visits to India. Fourteen semi-structured interviews over three visits were conducted in India and seven interviews in the two visits to the England-based staff, five were repeat interviews. The interviewees from both sides included senior management and programmers. Table 2 summarises the interviews conducted.

A round of interviews typically lasted most of a day when we would sit in the meeting room and sequentially interview a number of people. In between the interviews, we had the opportunity to observe the office layout, how people worked together, and the kind of activities that took place in the course of normal everyday work. These observations were also interspersed with informal conversations sometimes while having a coffee break or lunch. In addition to all these face-to-face interviews, we also conducted one telephone interview from England with the India office manager. This was in order to gain feedback on a report that we had submitted to them about our interpretations of the issues that we felt were problematic to the relationship.

The interviews were semi-structured and typically lasted for around one hour and the interview tapes were all transcribed verbatim. We did not have predetermined interview protocols but had sets of issues, which we felt were important to discuss with the respondents, and these issues changed with time. For example, in the initial set of interviews we focused on developing a historical reconstruction of events prior to the start of the study. These issues included understanding the nature of the feasibility study conducted prior to establishing the India centre, and the kind of links that had been established with local entities like universities etc. Subsequent

Table 2

Summary of interviews

\begin{tabular}{llllllll}
\hline & India & & & & England & Total \\
\cline { 2 - 3 } & $8 / 98$ & $7 / 99$ & $1 / 00$ & & $10 / 98$ & $10 / 99$ & \\
\hline Managers & 2 & 5 & 1 & 1 & 2 & 11 \\
Programmers & 2 & 4 & & & 4 & 10 \\
& & & & & & 21 \\
\hline
\end{tabular}


meetings focused on understanding ongoing challenges, for example related to the problems of attracting and retaining knowledge workers, the kind of project related problems that were emerging, and how they were being dealt with. Table 3 shows the categories that we used in early interviews to structure initial data collection.

Secondary material included a wealth of information on the corporate web site including press releases, corporate details, and related trade data. Research diaries were maintained recording our interpretations, thoughts and feelings during the course of the inquiry.

A first step in the analysis process was the creation of a summary document following a round of interviews in England or India. The basis for the preparation of this summary were the transcripts of the different interviews conducted, the field notes and observations made by the researchers. Intensive reading of these transcripts and notes, followed by iterative discussions between the researchers over email, telephone and face-to-face meetings wherever possible, helped to produce the summary. Wherever possible, we used tabular data displays (Miles \& Huberman, 1994) as shown in Table 5. This process helped to improve the communication between the researchers and also to improve our individual understanding of the issues and the relationship between the themes. The summary document included a description of the issues that were emerging; our observations, comments and interpretations, and an identification of the issues and themes that we felt needed to be explored in the future, both empirically and theoretically. In keeping with the interpretive tradition, where the data is the subjective interpretations of the respondents and the researchers, we tried to link the identified themes with quotes from interviews. The active involvement of both the researchers in the process helped to provide for multiple and alternative interpretations.

A second step in the analysis process was the preparation of management reports that we submitted to the senior managers of both Sierra England and India. Keeping in mind the readership, this report was quite different in structure and length from our summary document, which was primarily for our internal purposes. In this management report, we tried to concisely identify the problematic issues in the relationship, a description of why we thought it so and our suggestions for action. We submitted two such reports during the course of our research, which helped us not

Table 3

Initial categories for data collection

Projects. Activity types, nature of projects, work organisation. Procedures, standards; documentation, communication. Team organisation, interaction, control; reward, scheduling

Organisation. Management structure, formal goals, strategies; control and authority mechanisms, organisational form, hierarchical relationships; decision making processes, biographical details of key leaders. Production processes and sequence. Sales, nature of customers and profit. Intellectual property. Human resource strategies: retention, career structure, other schemes around human resource

Industry and the wider system. Industry level issues in environment, competitors, maturity, time in

market. Characteristics of physical locale. Broad socio-economic conditions. Data on the group and other companies. Competitive pressures

Use of ICT. What ICT are in use for co-ordination and control. Issues and effectiveness 
only to maintain our research access, but also served as a vehicle for obtaining multiple perspectives, that of the respondents, on our interpretations. Feedback received from the respondents on our report helped to clarify our own understanding of the issues that we raised, and also identify some other issues that we may have missed out.

A third, although not sequential, step in the analysis process was our efforts towards theory development. The theoretical development, like the research, also evolved over time. Initially, we considered Giddens (1990) ideas on modernity to make sense of the interesting question of why Sierra, who had established their India operations full of hopes and expectations, had to shut it down some 2 years later full of remorse and disappointment. An initial analysis of this case based on Giddens was presented by us at an international conference in 2000. Suggestions from the audience broadly pointed to the importance of considering knowledge-related issues, and we were guided towards Blackler's (1995) "images of knowledge." While we found Blackler's images to be useful in sensitising us to the "different kinds of knowledge" in offshore outsourcing, we felt it limited in understanding the process aspects of knowledge. We subsequently explored the "community of practice" (Lave \& Wenger, 1991) perspective that we later found limited in understanding the embedded nature of knowledge. This led us to develop the ideas of embeddedness which forms the basis of this paper.

In summary, our analysis process cannot be described in terms of a methodology that is rigorously predefined, but as a process that is based on interpretive principles. This involved the need to consciously solicit multiple perspectives, being iterative in nature, and being based on an active dialog between theory and empirical work. While we did not attempt to follow the grounded theory principles of Strauss and Corbin (1990) for example, our analysis approach can be described to be broadly inductive in nature. While the starting point was provided by the practical challenges facing the relationship, the subsequent trajectory of the research was shaped by our reading of the literature, discussions with Sierra staff and our research colleagues.

\section{Case description}

\subsection{An overview}

Sierra is a small but highly profitable and rapidly expanding software house with headquarters in London and a subsidiary in Bangalore. Sierra specialised in the development of short lifecycle custom-built client server projects covering a variety of customers and projects. In 1998, Sierra had particular strengths in visual interface design and in 1999, they moved into e-commerce development. In 1998, Sierra employed 80 staff worldwide, with a corporate revenue turnover of approximately $£ 8$ million. Like many other specialist software houses, Sierra management were striving to overcome skills shortages and capacity problems in England. Their response was to open a subsidiary in Bangalore, India. Sierra management believed that they could not pursue their strategy of corporate growth at their desired quality 
levels if they depended on the development resources in the South East of England. This was due to the high salaries required for qualified staff.

Prior to setting up their subsidiary, Sierra had attempted to outsource small projects to Indian software companies by "body shopping" of Indian staff to work in the head office. A key problem in these early attempts was the large variability in the quality of staff due to the frequent movement of developers, which influenced software quality. Another problem described to us was that of the outsourced staff not being well integrated with the England-based staff. For example, incentive schemes offered to Sierra staff were not offered to the Indian outsourced staff, and it was unclear whether the loyalties of Indian outsourced staff were primarily to Sierra or their home company. The outsourced staff felt no obligation to attend meetings or engage in informal socialisation and tended to keep to their own group. As a result, the Sierra management felt they had no control over the outsourced staff, and with time the development staff became increasingly factional.

Sierra management felt that the problems of inconsistent quality and lack of control could be addressed by opening up their own subsidiary. The early experimentation had given Sierra management the confidence about the availability of the necessary skills to undertake software development in India, and heightened their realisation of the need for closer control. A decision to open the India centre was taken based on a hastily constructed business plan. Within 3 months from the decision to start, a subsidiary was opened in Bangalore in 1998 with a modest growth plan from 10 to 24 people in 18 months. The initial aim of Sierra was to create "a little bit of England in India" shown in the expressed desire to migrate the head office organising principles to India. Early projects involving the Sierra India centre varied in size and scope but were typically short lifecycle projects involving mainly data warehousing and interface design. We describe the process by which the relationship between the head office and Indian subsidiary developed in two phases of initiation and growth (1998-1999) and maturation (1999-2000). The relationship failed to stabilise, and the subsidiary was subsequently shut down.

\subsection{Initiation and growth phase (1998-1999)}

The manager of the Indian subsidiary (whom we call Mitra) was of Indian parentage, born in Kenya and raised in England with a computer science education. The decision to deploy Mitra to Bangalore was influenced by his Indian parentage, which it was felt could help bridge some of the background knowledge of the India context. Mitra was expected to create appropriate conditions for participation of the Indian team with the project activities of the Sierra head office. However, Mitra had never lived in India and had only superficial knowledge of differences in the social structures of England and India. He believed that software development was a "global profession" with strong, homogenous norms of practice. Mitra and a colleague of his, who had been involved with Sierra's earlier outsourcing attempts in India, were responsible for setting up the Indian centre. In hindsight, taking into account how later events unfolded, these early experiences seemed to have provided Mitra with very little local contextual knowledge or subtle understanding of "the way things are 
done" in India. For example, the Sierra management did not realise the need for a so-called "middleman" to negotiate with the Indian Customs officials to release their videoconferencing equipment, or to get their telephone connections expedited. The resulting delays caused frustration to the Sierra management in England. This negative situation was accentuated with the resignation of Mitra's expatriate colleague in India 4 months after the subsidiary operations started. Along with the loss of a close ally, Mitra also lost access to this person's accumulated experience of doing business in India over the previous few years.

Sierra's initial plan was for the Indian team to take whole lifecycle projects including all customer liaisons. Sierra management tried to establish a direct interface between the Indian developers and their England-based end clients. A variety of technologies were used by the staff to enable collaboration and sharing of routines and procedures (shown in Table 4). Sierra management in India and England were optimistic about how the use of ICT would make "distance invisible" between England and India and provide the conditions of full participation between the England-based clients, head office and the India based staff. It was envisaged that system requirements could be easily elicited and transmitted to the Indian developers. A head office manager remarked that now "geography is history". The Bangalore centre could be made to operate in a seamless way, appearing to their England-based clients as if they were physically present in England. Usual procedures in the head office that involved regular face-to-face meetings with clients every 10 days could now be replicated over the telephone or videoconferencing connection. The use of a leased line would mean that customers did not have to pay extra for the call, which in turn was expected to encourage communication. Mitra was confident that the knowledge gained through their early outsourcing experience supported by the use of ICT could effectively substitute for the need for face-to-face presence.

By the end of 1998, the Bangalore subsidiary had engaged in some full lifecycle projects but even in those instances videoconferencing had not offered the expected levels of inter-staff interaction. Contributing to this were technical reliability problems due to frequent power failures in India, and also because the videoconferencing link was to the Sierra London office. This meant that Sierra's customers, often out of London, and typically without access to videoconferencing equipment, had to travel some distance for the conferencing session. This was practically inconvenient and

Table 4

Use of ICT in the relationship

\begin{tabular}{ll}
\hline Technologies & Purpose of use \\
\hline Staff intranet & Shared database of standard procedures for quality, project \\
& management, systems development, appraisal, career development \\
Email & Send receive of asynchronous messages \\
Video conference & Synchronous video conference \\
Telephone conference & Synchronous group discussion \\
Internet netmeeting & Demonstration, speech, whiteboard, synchronous text chat \\
\hline
\end{tabular}


impeded the effective use of videoconferencing since it required a great deal of logistical co-ordination of activities in terms of both time differences and multiple locations.

Communication was also problematic because customers and head office development staff found the "strong" Indian accent difficult to understand. This was made worse by unreliable video and audio conferencing links. In one "success story" related to us, a majority of the early lifecycle work (analysis and design) was done by an Indian developer who travelled to the client site in Southwest England for several months to facilitate the process of requirements elicitation. The developer felt that such face-to-face contact was essential to reassure the customer and to help the Indian developers in Bangalore understand the complexity of the requirements. $\mathrm{He}$ felt that the initial interactions provided him with the shared frame of reference with the England-based customer and colleagues which enabled effective ICT-mediated communication on his return to India.

\subsection{Failure to reach maturity and closure (1999-2000)}

In early 1999 after several (mostly unsuccessful) attempts at whole lifecycle projects being undertaken in India, it was felt by Sierra management in England and India that the model of work distribution should be moved to two discrete and largely independent models. Model one, which had been in use prior to 1999, envisaged the use of a split team between head office and subsidiary. Teams were comprised of subsidiary and head office staff, varying in size, but usually with 4-5 head office based developers collaborating with 2-3 Indian staff. Subsidiary and head office staff either travelled back and forth, or a head office liaison was used for requirements elicitation and ongoing customer interaction. As well as the difficulties of communication related in the earlier phase, a lack of physical proximity was identified as a key problem with this model.

In model two, projects were broken into self-contained modules and the India team assumed responsibility for an entire module but the head office team would do most or all the customer liaison. In this model, specifications would be sent to the India team and the code returned for testing and aggregation into the completed application. A mirror of the application as built was maintained at both sites. Videoconferencing, email and telephone as well as Microsoft Net meeting were used to facilitate communication between developers, and also to a limited extent with customers. File Transfer Protocol (FTP) was used to deliver completed portions of code. Most work would be undertaken with the latest Web application building packages, JavaScript and database applications.

In model two, the strategy was one of replicating knowledge systems and minimising the need for continuous interaction between head office and subsidiary. Model one emphasised the development of knowledge sharing bridges through travel and the use of ICT. Sierra head office staff considered model two more effective since the modularisation of work done in India made it self-contained and minimised the need for subsidiary-head office interaction. Although Sierra management considered the model two strategy more successful, it was not without problems. For instance, 
the head office staff perceived the subsidiary staff to have difficulty in keeping up pace with the England side.

By mid-1999, the "dotcom boom" had begun and Sierra's business direction was being reoriented towards providing e-commerce solutions. The e-commerce area itself was nascent and clients were rather unsure of what they wanted. This industry situation made Sierra management feel that they had the opportunity not only to implement solutions but also to define problems for the clients. Sierra as a company consequently needed to pay greater attention to the client's business needs, including their information strategy requirements. This implied different knowledge requirements from coding to consultancy, problem solving and presentation. There was subsequently within Sierra a complex rethinking of their future strategic thrust. There was a general consensus that for the highly complex and early lifecycle projects that e-commerce applications entailed, the Indian developers would need to be onsite with the customer. From the customer perspective, there were also serious concerns about intellectual property, especially in a new and uncertain area like e-commerce where ideas were valued more than the product itself. This was the primary concern, which led Mitra to believe that Sierra customers would be reluctant to outsource their e-commerce ideas and plans to India for fear of intellectual property theft. To deal with the new strategic need for onsite work, and the ongoing problems of running the Bangalore office, Sierra decided to close its India operations and relocate the staff to the head office in England.

\section{Analysis: implications of embeddedness}

In this section, we elaborate on the nature and implications of embedded knowledge at the three levels of analysis: societal, organisational and cognitive. Two key areas are discussed. Firstly, we discuss how organisational principles of project management are nested within societal level structures and also at the organisational and individual levels. This embeddedness had significant influences on project management, especially related to issues of "timeliness." Secondly, we discuss Sierra's organisational level principle of nurturing "creativity and learning through conflict." We discuss the difficulties experienced in applying this principle from the Sierra head office to India due to different societal and organisational conditions, and how individuals in India appropriated these practices quite differently. These two points of analysis are first discussed and then summarised in Table 5 at the end of the section.

\subsection{The organising principle of project management}

A significant feature of Sierra's project management practice concerned the principle of leakage, which served as an indicator of the ability of a software team to complete a project in the specified timeframe. Leakage was used as a primary measure in the England centre for evaluating project success and leakage rates for all projects were recorded and displayed publicly on the notice board in the England 


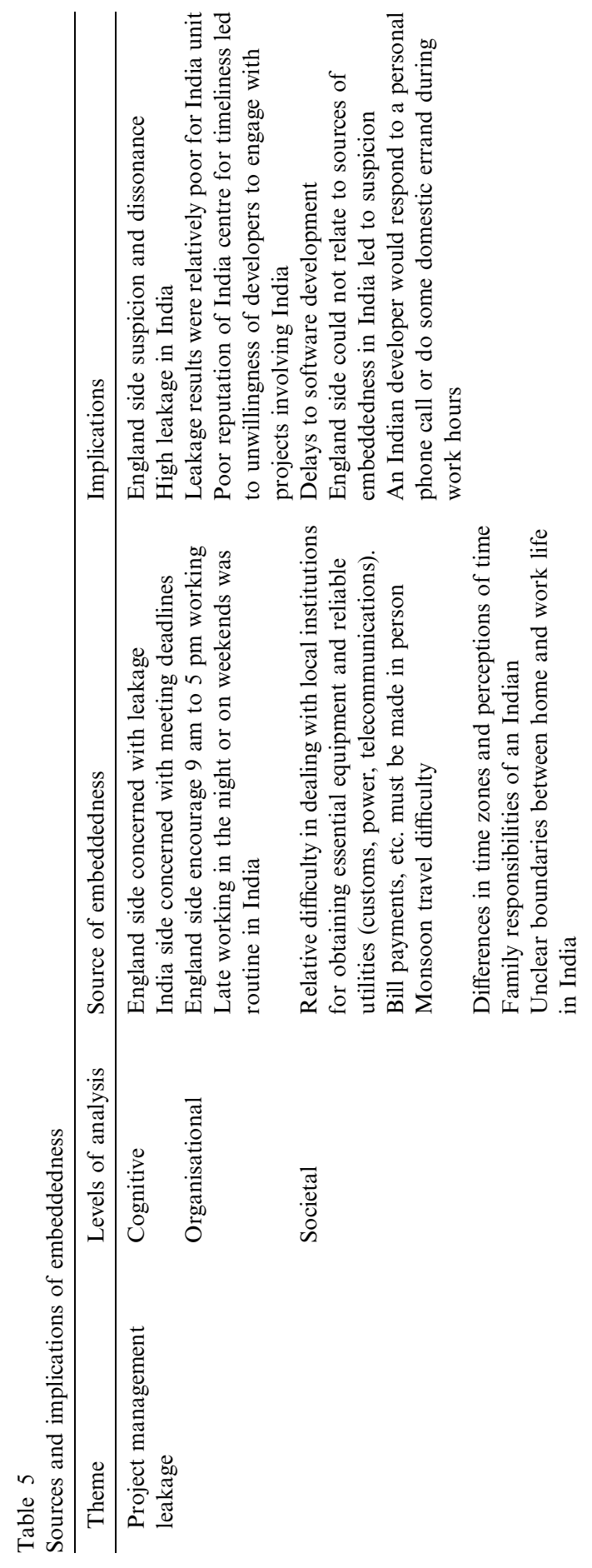



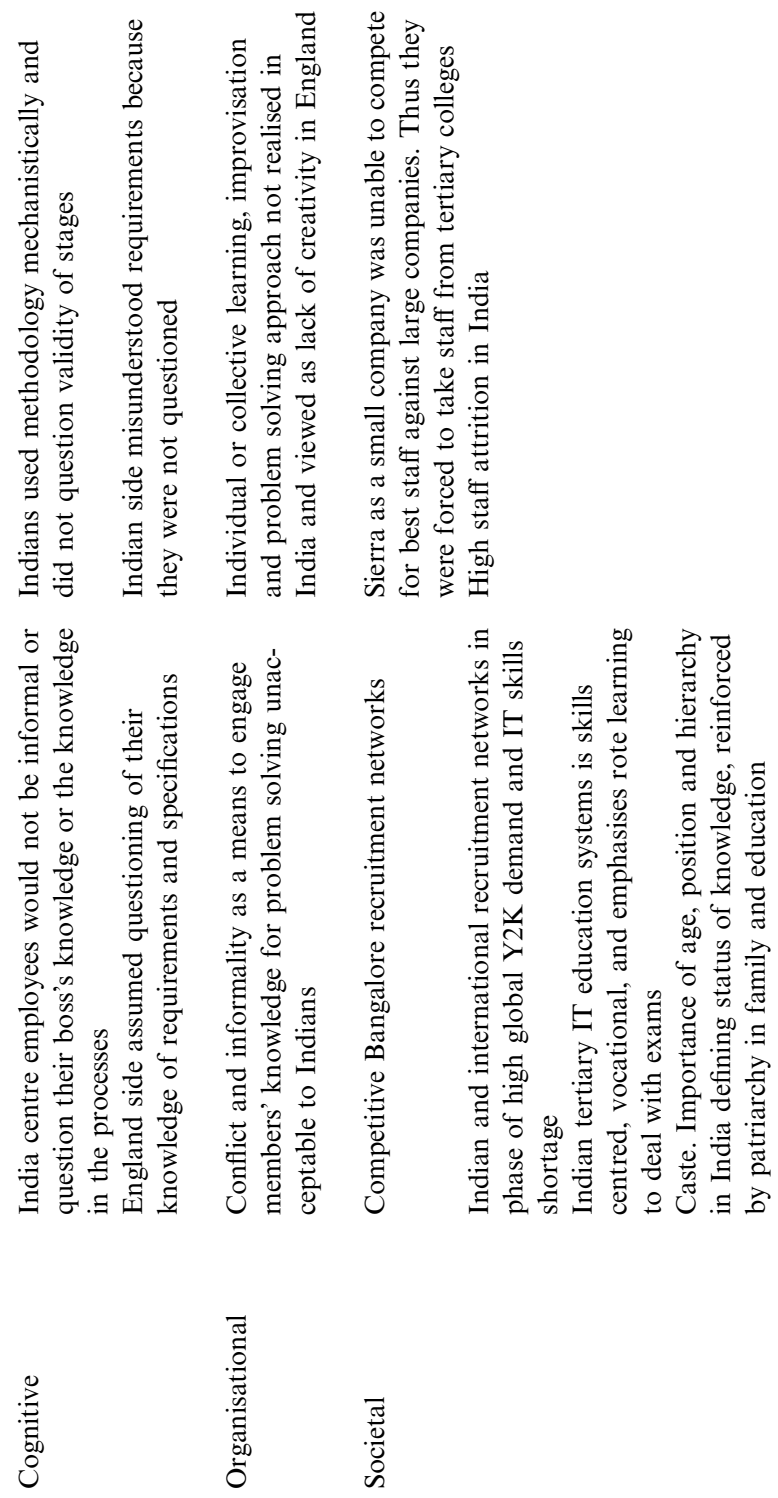

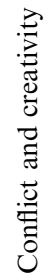


office. Leakage was thus an important project management measure that translated into the appraisal of project managers both formally and informally. We were told by a Sierra England-based manager that "a good project manager's reputation was built and maintained by sustaining low leakage levels". Leakage thus represented an important organising principle.

For reasons of consistency, to measure the success of the India unit and for appraisal of individuals, Sierra management at the outset decided that identical project management routines including leakage should be migrated to India. When migrated, leakage was found to be difficult to apply in the Indian subsidiary. Mitra and the head office management told us they were unhappy with the subsidiary developers where projects were seen to be "leaking" about $25 \%$ over project estimates. This was significantly higher than the head office average of less than $5 \%$. However, when we confronted the Indian developers with this claim of poor performance we found them to express surprise that leakage was an issue of concern since they believed they had been delivering projects to deadline. An Indian developer in Bangalore told us:

Leakage has been an issue to address. There is a thinking difference between Sierra in England and us in India and we had to try and bridge it and get everyone to appreciate the value of time and that 8 hours means 8 hours. That doesn't mean you can stay all day and finish in 12 hours and say I did it, my commitment was for tomorrow morning.

On further exploration of this issue, we found this difference of opinion was due to very different interpretations of leakage by the Indian and England staff. The head office measured leakage based on the number of hours worked on a project and not on whether or not a deadline was met. The Indian developers in contrast interpreted leakage as based on whether a deadline was met or not. For example, if the England office set a deadline for delivery of Monday morning, the time allocated for the project was based on the assumption of a Friday evening $5 \mathrm{pm}$ stop. However, it would be quite typical for the developers in India to work late in the evenings or over the weekend to make sure they met a deadline. However, the head office management perceived this as leakage if it involved a greater number of hours than originally assigned for the project, even if the project was delivered "on time."

Instructions about the importance and the manner in which leakage was computed were clearly detailed on the Sierra staff intranet. Mitra told us he had explained these rules to all developers and stressed the importance of adhering to leakage stipulations on many occasions.

The difficulties in migrating the leakage principle can be explained with respect to embeddedness of knowledge at societal, organisational and cognitive levels. In the London office, as is often common in many western societies, time was treated in a chronological manner, reflecting a clear and sequential segmentation of activities (Hassard, 1999). The staff we met at the head office tended to practice a relatively clear separation between home and work and they were strongly encouraged to work a regular 9 am to 5 pm, five-day working week. A staff member in England said that 
when a developer comes to work, he or she would not respond to a personal phone call or leave the office to undertake a domestic errand during work hours. The following two quotations from Indian developers in Bangalore reflect the contrasting organisational and individual practices in England and India respectively:

People have told me that in England no-one will pick up a phone call which comes in from his home, he will say 'I will call you back when I am finished with this work' whereas here we would pick up the call.

Here (in India) people will spend a fair bit of time on the phone to family and friends. We compensate for that by staying a little later, and we will get the work done within the number of days.

Furthermore, we were told that it was a common and accepted organisational practice for the Indian developers to take 2-3 hours off in the middle of the workday to take a relative to the hospital, or to pay a telephone or an electricity bill. This needed to be paid personally rather than by post or through the bank, as would have been the customary practice in England. This "off-time" would later be compensated for by the developer working late in the evenings or over the weekends. However, under the existing project management routines all of the developer's "work time" had to be accounted for. Any time spent on the telephone, paying bills or taking relatives to the hospital etc. detracted from the time estimated to be spent on the project, thus contributing to "leakage."

These individual practices, legitimised within the organisational context, need to be understood within the broader societal structures existing in India. These include the relation between home and work lives, and the level of existing infrastructure. In India, home and work lives tend to be more intertwined than in western country contexts where they are more sequentially separated (Sahay, 1997). In Indian society, the concept of a joint family system is relatively strong, for instance it would be common for young developers to be living together with aged parents. Since health care for example is primarily a responsibility of the family rather than the state, it is quite accepted, even in formal organisations, that an individual will need to periodically take time away during working hours to take a sick person from home to the hospital. Infrastructure conditions existing in India contrast with the England situation although the situation is much improved than a decade ago. Telecommunications failures and power cuts are still relatively common occurrences in Bangalore, which significantly affect developer productivity. During the Indian monsoon it can be extremely difficult to travel causing occasional delays or absence of staff due to flooding on the roads and traffic congestion that ensues. These conditions added to the complexities of synchronising time differences between India and England, and often led to significant periods of "idle time." An Indian developer in Bangalore reflected on these delays:

I can be waiting around for some hours for England to come in to work so I can clear up a query with a colleague. There is sometimes nothing I can do until they come in. 
Whenever the link is down it causes problems in that we are waiting for a reply from the other side.

Further contributing to delays in India was the need for bribes to be paid to representatives of institutions such as telephone and electricity services. This practice was not understood by the Sierra England staff. This knowledge about bribes is not explicitly discussed or documented, but is an institutionalised practice of many Indian public organisations. Telephones took considerably longer to be installed and repaired than in England and large bribes were ultimately required to be paid to get equipment, for example videoconferencing, through the customs. These problems led to delays, which were never fully appreciated by the England-based staff. It contributed to the overall impression of the workings of the Indian centre as being fraught with delays, and having significantly higher leakage rates.

In summary, migration of the knowledge residing in the leakage routine was problematic due to its embeddedness in the Sierra England context making it incompatible with the India context. The different understanding of leakage in India was derived from the societal, organisational and cognitive levels of analysis. At the societal level, the structures especially around family and work lives, infrastructure conditions (roads and telephones for example), and institutionalised practices of utility providers and customs authorities, all contributed to different organisational and individual working patterns as compared to the England setting. These different patterns of work found legitimacy in organisational routines, which for example did not penalise someone from taking off for a few hours of their working day as long as that was subsequently compensated. These societal and organisational conditions were furthermore nested with the cognitive frames and everyday practices of individuals in the course of their everyday work.

The context in which leakage was conceptualised, understood, and practiced in England was very different to that of India. These differences were very difficult for the England head office staff to comprehend in the absence of a exposure to the societal and organization life in India. As a result of these rooted differences, the organising principle of leakage was experienced to be largely "non-migratory" and not possible to implement unproblematically in India. As a result of this ineffective migration, a number of significant consequences ensued. Firstly, project delay from the Indian staff was seen by the England staff as being extreme and unacceptable. Secondly, the attempt by Mitra to try and explain the delays led to the England staff viewing him with suspicion and as making excuses to compensate for his inefficiencies. Thirdly, it contributed to the view in England that the Indian team was largely incapable of dealing with more complex projects where timeliness was an important consideration. These different adverse consequences ultimately contributed to the closure of the India development centre.

\subsection{The organising principle of "conflict enabling creativity"}

Sierra England placed a high premium on the value of creativity amongst their employees. This was expressed through formal reward and recognition schemes and 
various informal practices. These were manifested through organisational principles such as an open office layout, casual dress code, flat organisation structure, and a flexible decision making process. Statements from several England-based staff reflect the manner in which creativity was understood in their organization:

Creativity is the ability to 'self-start' and 'think outside of the box.

Developers in England can use the software analysis and design techniques flexibly, question assumptions and think independently largely without supervision.

A similar notion of creativity reflecting values of initiative, "thinking outside the box", an informal style, and informal social interaction were also emphasised in the Sierra marketing literature. Some quotations are shown below to illustrate this emphasis:

Our project managers think about your projects shape rather than applying the same old formula every time.

We arm our people with a toolbox of techniques not a single rote methodology that cramps their creativity.

Out of the box thinking means willingness to take new perspectives, openness to doing things differently, finding new ideas and acting on them and striving to create value in new ways.

We believe in an informal structure and an environment where everyone can make a contribution to the success.

People have multiple roles, and are expected to do what they can to contribute to the priority areas. We have open-plan offices where everyone can interact, a merit-based career structure, and an active social scene. People understand the business and each other. They bond well together on teams and share their know-how, making Sierra a productive and enjoyable place to be.

In London, the Sierra office was laid out in open plan style for "hot-desking" using lap top computers and mobile phones. All staff typically dressed informally in jeans and t-shirt and senior staff often shared desks with junior staff. After work hours socialisation in the pub was a tradition, and involved senior and junior staff "downing a few pints" together. These events helped to legitimise informality, to nurture "questioning behaviour" irrespective of hierarchies, and enable information sharing through personal and informal networks even outside the work place and time settings. These organisational principles emphasised that the Sierra staff were expected to challenge the assumptions of others, even the Managing Director, and be capable of independent thought and self-learning. The head office management perceived that a knowledge worker's ability to question assumptions and raise problematic issues publicly, even if it was confrontational, was key to knowledge sharing, improvisation and problem solving processes during software development. 
The Sierra management believed Sierra India should become "a little bit of Sierra in India," and should mirror the non-hierarchical, informal, and confrontational organising principles as the vehicles to mobilise creative behaviour. For example, some meetings in England were videotaped and sent to India as a means to demonstrate how they were expected to conduct similar meetings. This was also to make India based staff feel part of the broader Sierra team. These tapes showed England-based staff expressing conflict in highly volatile and supposedly "creative discussions" as a basis to encourage improvisations, team learning and problem solving. In these monthly meetings, which involved members from all levels, junior developers would openly confront and contradict senior staff members, and informal stories would be exchanged on how prior problems had been solved. The Indians were surprised that such styled meetings were also used to define formal activities like the firm's strategic direction, plans and forecasts. There were many instances where developers in the meetings from different projects after a heated discussion would agree to meet up later, maybe in the pub, to examine a problem and its solution in detail.

To an external observer, such as us or the Indians watching on videotape in Bangalore, these discussions seemed very heated and acrimonious, and raised questions on how harmony could be restored so soon after. In addition to being deeply confused and perplexed by the nature and structure of the creative discussions which involved shouting and swear words, the Indian staff also found it difficult to understand the strong English accents. As a result, when this principle of "creativity through conflict" was attempted to be replicated in India, the Indian staff refused to openly contradict one another or their manager. Mitra was frustrated by this reluctance, as he perceived this as an absence of creative ability in the India based staff. The following comments from Mitra express this frustration:

In India the hierarchical position or 'tag' reflecting status, title, rank and position of a person were more important than the knowledge the individual brought into the process...I am uninterested in titles and rank and only concerned about what someone brings to the table in terms of direct contribution to solving the problem or issue at hand.

I am not allowed to enter into their (the Indians') comfort zone. I am 'the manager', they will not let me talk to them and they will always agree with me. In meetings, the staff often stay quiet but I will get a lengthy email maybe an hour later after the meeting is over. And I have to start the thing all over again. And I think, well why not bring all that up in the meeting? It ends up taking twice the time. They do not confront me in meetings. The creative spark is missing.

It is really annoying. Sometimes I tell them something that is wrong. I want to hear 'I don't agree with you.' Here they are all interested in the 'tag.' I am more interested in what you bring to the table, not the tag you bring.

Mitra seemed quite convinced that the Indian developers lacked a "spark", were unable to "self start," or engage in "self-directed learning". Mitra's views were mirrored by staff in the England office and a senior manager there said: 
It is a sweeping statement, but in India they don't tend to think outside of the box, they do what they have been told to do. And what that means is that if you miss something or something doesn't quite add up, they won't see it as a problem that they need to solve independently. They'll read that as what to do. So you have to be aware of that problem. I think that they will see there is a problem, but think that it is sorted out by someone senior. We want to encourage the developers to think outside of the box and to raise questions and issues.

In contrast to the England-based staff, the Indian staff in Bangalore preferred their own enclosed and defined workspace and also tended to dress more formally than the England staff. The behaviour at social events was also quite different, which contributed to Mitra's frustration. Mitra complained:

The London office is much freer. A typical example from the London office might be when someone new joins us we open a bottle of champagne. People casually mill around, say hi and move-on. Here in India, I am expected to make a speech. $20 \%$ drink, $80 \%$ don't. We have some soft drinks for them to get people to loosen up. In the London office everyone drinks.

Failure to establish such informality, including a drinking culture, and conflict in India had specific implications for how information and knowledge was shared and appropriated by individuals. Software development methodologies placed on the intranet, were perceived by the head office to serve as general guidelines rather than as highly prescriptive structured instructions. An Indian staff member in Bangalore acknowledged the constraints in how these guidelines were appropriated by individuals:

I was earlier in an ISO9000 company where the instruction was 'you need to have this documentation.'

Here we are given flexibility. You decide what is in the document, it is not just being flexible you decide if it is required. We have to get away from the idea of being given the design and coding, and try to be more innovative and have our own ideas.

What is striking in Sierra is that you get responsibility that you don't expect to get. In other companies you are shielded quite a lot, you are exposed a lot more here. Some people don't like it...you have to be innovative, have your own ideas and think wider to survive here. That was not the case in another company I worked for when there are hundreds of people on the project and things were defined.

The head office staff perceived the Bangalore based developers to use the guidelines "mechanistically" and in a linear fashion without questioning the validity of statements. One England-based developer told us how informal norms in Sierra England sanctioned deviation from the standards:

The Indian staff would go through steps and stages that would have been modified or left out if the job had been done in London. 
An Indian developer in Bangalore provided this explanation for their adherence to instructions:

Indians are not too good at taking decisions. If it is unclear where to make a decision then we might ask. People in England seem to make decisions independently. It is unclear when you should go on and when you should ask. This relates to the way we are brought up. You don't want to step outside whatever rights you have.

In a continuing effort to imbibe the Sierra head office notion of creativity and informality, staff from both locations were taken on a combined trip to the seaside resort of Goa. However, these efforts to create a relaxed atmosphere were difficult to translate into the reality of the office. Once the staff were back in place, socialisation attempts between London and Bangalore based staff turned out to be limited, also contributed to by the constraints imposed by the ICT environment.

High levels of staff attrition, a characteristic of the Indian software industry, meant that a lot of energy was expended on constantly building new relationships, and to share required project knowledge repeatedly with new staff. Attrition thus further impeded the development of enduring and strong social ties, already limited through the ICT interactions. Far from the "streets of Bangalore being paved with programmers," as Mitra had originally thought, he quickly found Sierra was a very small company competing for the best staff with large multinational corporations. These multinational corporations were hungry for qualified Indians to work for them, especially on the $\mathrm{Y} 2 \mathrm{~K}$ projects in demand at that point. The overall demand for qualified staff exceeded their supply (Arora, Arunachalam, Asundi, \& Fernandes, 2001). A large majority of the pool of Indian software professionals tended to have an engineering education, where mathematical problem solving skills, techniques to think logically and learning to use state-of-the art tools were emphasised. Graduates from the leading engineering universities, such as Indian Institute of Technology, represented the "creative" skills and qualities that were required by Sierra. However, in light of the stiff competition experienced from the more glamorous and sought after multinational corporations, Sierra could not obtain the appropriate staff they required. They had to make do with graduates from the lower end engineering colleges where the education focus was on providing technical skills (like programming languages). This was in contrast with a broader based education that would also emphasise the development of critical thinking and a broad business understanding.

On analysis, Sierra England's organising principle of "learning through conflict" could not be effectively migrated from the England context to the Indian situation. Knowledge embedded in the England context at various interconnected societal, organisational and cognitive levels could not be replicated in India due to the existence of a very different context. Sierra England's relatively flat structure was very different from that in many Indian firms. In such firms, prior research argues that obedience is expected from junior staff members, and guidance is expected from senior leaders. The knowledge that seniors have has a higher status than that held by juniors (Sinha, 1984). 
The organisational principle of creative, confrontational meetings, considered legitimate and necessary in England, was seen as inappropriate in the Indian organisational context. The England routines of confrontation were at odds with the "check with the boss" style of decision making so dominant in Indian organisations (Sinha \& Sinha, 1990). These organisational decision making practices have also been related by other researchers to their nestedness in the societal level. Indian family structures that values hierarchy reinforced by the enduring influence of caste in Indian society (Sahay \& Walsham, 1997).

These sources of embeddedness of knowledge in societal and organisational conditions are reflected in the routines of individuals. For example, Indian developers preferred to be given structured methodologies and instructions to follow rather than engage in improvised behaviour and take decisions on their own when faced with conditions of ambiguity. This lack of self confidence of developers was rooted in the vocational, skills focus of the engineering colleges from which Sierra's staff were recruited as compared to the critical, problem solving curriculum of engineering graduates from the Indian Institutes of Technology. Sierra was unable to attract these graduates and the India centre was staffed with developers educated in relatively lower tier institutions. This position was shaped by the societal demand and supply conditions of software staff and Sierra's inability to compete effectively with large multinationals in Bangalore for the most highly skilled and qualified staff.

The inability of Sierra to migrate the organization principle of creativity through conflict had a number of significant influences on the evolution of the relationship. Firstly, it contributed to an extreme frustration in Mitra, a feeling that was gradually transmitted to the England office leading to an overall negative perception of the India office. Secondly, it also contributed to some breakdowns in transfer of design specifications to India, as the Indians could not deal with ambiguity independently. The England staff expected them to ask questions where things were not clear or deal with the problems on their own. We were given various anecdotes of incomplete or wrongly interpreted design. Thirdly, issues took longer to resolve in India as Mitra expected that issues could be closed through direct meetings, but opinions were often expressed later on an email needing further rounds of discussions. In Table 5, we summarise the analysis presented above by describing both the organising principles and the different sources of embeddedness of knowledge at the societal, organisational, and cognitive levels, and its implications on the management of the project and the relationship.

\section{Discussion}

The analysis of the embeddedness of knowledge in offshore software development has helped to identify some of the barriers facing migration of organisational principles across different contexts. These barriers have been related to the manner in which these principles are embedded at the interconnected societal, organizational, and cognitive levels of analysis. The study reinforces Lave and Wenger's (1991) 
argument of how activities, tasks, functions and understanding do not exist in isolation; they are part of a broader system of relations in which they gain meaning.

We have illustrated the challenges associated with the embeddedness of knowledge in local contexts with two interesting episodes drawn from our empirical analysis. This analysis contributes to a richer understanding of the dynamics around how knowledge codified into organisational principles in one context is difficult to apply in another. This can be explained with regard to embeddedness of knowledge residing in these principles embedded in broader societal, organisational, and cognitive concerns. As a result, organisational principles, which can be used to mobilise knowledge in one context may be difficult to apply in another. We identify four key contributions arising from our analysis, which relate primarily to the issue of how the challenges related to embedded knowledge can be theoretically understood and more effectively managed. These four areas of contribution, the first two theoretical and the remaining practical, are:

- A more subtle theoretical understanding of the embedded knowledge in the context of offshore software development.

- An understanding of the challenges of disembedding knowledge described by Giddens (1990) to be a key feature of globalisation.

- The role of "straddlers" in managing the challenge of embedded knowledge in software development.

- The implications for small sized firms (like Sierra) to manage offshore software development processes.

\subsection{Theoretical understanding of the nature and implications of embedded knowledge}

Our starting point in theorising about embedded knowledge was provided by Lam's $(1997,2000)$ analysis of the challenges of embeddedness in a collaborative technology project involving British and Japanese firms (1997), and subsequent theoretical model around the embeddedness of knowledge (2000). We believe our contribution goes beyond Lam's analysis in at least four distinctive ways.

Lam's earlier work (1997) is developed on an empirical analysis, while her later paper (2000) develops a more theoretically informed model of dominant knowledge types and organisational forms. While not specifically stated, her theoretical model is informed by the earlier empirical analysis. A first extension to Lam's study therefore comes from the application of the theoretical model to the domain of offshore software development. As argued in the Introduction, software development generally and offshore software development in particular, has very distinctive demands of knowledge, and thus needs to be treated differently from other kinds of technology development projects, for example related to manufacturing. The domain of offshore development is of increasing importance to the information systems research community, and there have been to date limited intensive empirical analysis of such relationships by information systems researchers (Sahay et al., 2003). Our study thus directly contributes to our understanding of this complex organisational phenomenon. We have also added further aspects to Lam's theoretical model. For ex- 
ample, at the societal level Lam discusses labour markets and educational systems as being crucial in determining organisational and individual dynamics. We have extended this analysis by also examining social structures, and not just formal institutions. In countries like India, we have argued that the social structures around the relation between work and home lives are also crucial as they serve as a source of embeddedness and contribute to make knowledge "non-migratory."

Lam's (2000) focus was on understanding how the links between the three levels shape the knowledge base and with it the learning and capabilities of firms. A third extension to her work comes in our application of these ideas in understanding specific project related outcomes. At each of the three levels (societal, organisational, and cognitive), we have attempted to identify the sources of embeddedness and the implications that arise for the management of knowledge, and how these shape project related outcomes. These micro-level dynamics, we argue, are crucial in understanding how to manage projects, and also to develop and extend theory based on empirical experience. For example, we describe how societal conditions of labour supply shaped the practices of recruitment and retention of Sierra staff. This understanding has direct implications on how management process can be strengthened to improve the recruitment of quality individuals, but it also helps refine our theoretical understanding of the linkages between individual identity, knowledge competencies, and processes of globalisation.

Unlike, Lam's (1997) setting which described a "dyadic" relationship between the British and Japanese firm, the offshore software development domain, the focus in this case is more dynamic and influenced by ongoing globalisation processes. For example, we describe how changes in the e-commerce marketplace and the global dotcom boom helped to shape processes at the societal, organisational and cognitive levels. In another example, we describe how the global supply and demand position of software developers shapes knowledge related issues at these three interconnected levels. These examples thus emphasise the need to consider a global level of analysis to Lam's (2000) earlier identified three levels. This extension we argue is crucial in the analysis of activities like offshore software development, which by nature is a global phenomenon. This point is our fourth extension of Lam's analysis.

\subsection{Globalisation, embedded and disembedded knowledge}

Writers like Giddens (1990) and Castells (1996) describe a distinctive feature of contemporary life to be the increasing interconnection between the extremes of globalising influences, institutional dynamics, and personal dispositions. A key mechanism enabling this interconnection, Giddens argues, is the manner in which knowledge can be disembedded from the local context, and rearticulated or reembedded in global contexts across time and space in the form of "expert systems."

However, Giddens says little about how these dynamics work in practice, and the local tensions that characterise such global phenomenon. As Walsham (2001a) argues, such macro-conceptualisations as offered by authors like Giddens while being useful in providing a high-level view of the landscape are limited in explaining the 
micro-level dynamics of particular organisational processes. High-level insights generated from social theories need to be integrated with in-depth, micro-level and processual analysis of particular work arrangements. In this case, it is related to how knowledge is constructed, understood, and the tensions that arise in attempts to migrate it across national and organisational boundaries.

Avgerou (2002) has argued that current commentators on globalisation (for example, Appadurai, 1996) are concerned with the extent to which globalisation implies preservation, and the diminishing of differences among social groups including organisations. At one level, this study could be argued to contribute to the relevance of "national society" and how knowledge remains locally embedded in its institutions and social structures. This is despite the attempts by large multinational organisations to homogenise global operations. Notably and Carmel (1997: p. 135) identifies characteristics of an "American culture of software" with strong similarities to the Sierra England organising principles. Walz et al. (1993: p. 70) "recommend consideration of formal techniques for managing conflict to help with knowledge acquisition, sharing and integration". National society explanations could be presented to explain how Sierra's organising principle of conflict would not be appropriate for software development in India. However, national society arguments assume homogeneity and do not fully explain the local embeddedness of knowledge. We have argued that graduates from the Indian Institutes of Technology could potentially have been able to engage in the desired creative conflict in the India centre. Embeddedness of knowledge is also not static, for example, recruitment in Bangalore in 2004 is easier than in the 1998-2000 peak due in part to an ongoing "reverse diaspora" of qualified India software development staff with experience of working in Europe and United States (Singh, 2003). This is in line with Avgerou's argument that "the context of action and more specifically organising action should be seen as an interplay of institutions in multiple social space: the sub-national local, the national, the regional, the global and the disembedded" (p. 113). Similarly, Lam argues:

Putting aside the "societal specificity" debate, a more fruitful line of enquiry would be to explore how such institutionalised variation may allow, or constrain, firms and countries in creating different organisational forms..." (2000: p. 209)

The organisational form around offshore development involving time, space and cultural separation, requires the migration of knowledge to be accompanied with a process of negotiation. It is only through this process of negotiation can locally specific knowledge around organising principles be understood by the various actors involved, and revised approaches developed. The Sierra case emphasised the absence of such negotiation with the focus from the very outset being to "create a little bit of England in India". Sparse attention was given to understanding the Indian context and the development of hybridised organising principles. The theoretical challenge here is to understand the conditions through which negotiations are enabled and inter-subjectivity obtained. In the next section, we argue that straddlers can potentially play an important role in this regard. 


\subsection{Role of straddlers}

When organisations need to collaborate in conditions of separation, mechanisms are required to "bridge" these physical and cultural distances. Authors such as Castells (2001) have forcefully argued that ICT are a necessary but not sufficient condition to try and bridge these gaps across cultures. Information systems researchers studying distributed development have argued for the key role that "straddlers" (Krishna, Sahay, \& Walsham, forthcoming), "bridgeheads" (Carmel \& Agarwal, 2002) and "shock absorbers" (Sahay et al., 2003) can play in trying to "bridge" the gap arising through the embedded nature of knowledge in the respective organisations and societies. These "bridge" people have the necessary skills, experience and qualities for the role of liaison between individuals and groups the purpose to help them to understand and overcome the difficulties of embeddedness of knowledge. Such people would have a subtle and sophisticated understanding of the nested cognitive, organisational and societal conditions in the respective global locations where development is taking place.

In the case of Sierra, Mitra was placed as the straddler who on one hand, had to convey the expectations of the England-based staff and their rules of doing business to the Indian office, and also on the other hand, "get the work done" in India. Mitra lacked an in-depth understanding of both the sides. He also lacked the necessary competence to "negotiate" knowledge between both sides of the relationship so as to develop more subtle understanding of the embeddedness of knowledge and how to deal with it. Through the close scrutiny we made of the case and the detailed and repeated discussions we had with Mitra, we strongly believe that Mitra was not an effective straddler. For example, he displayed a very superficial understanding of complex Indian structure when making statements such as "the streets of India are paved with programmers" or "I thought Indian developers would be motivated by fast cars, things to keep them amused." The first statement suggests he was taken up by the hype about Indian software capabilities and did not consider the challenges of trying to recruit the programmers in the light of the ongoing competition from large multinationals for the same staff. The second statement of Mitra reflects his lack of understanding of Indian social structures. Many Indian developers have desires of rapid mobility, quick money through stock options for example and global travel. However, these aspirations and desires are shaped within existing social structures. For example, often it may be found a developer will refuse overseas locations because parents are staying with her. Such a constraint may not be applicable in England where people often tend to live independently once they start to earn a salary.

Intensive and ongoing education for staff in respective global locations may be helpful in developing empathy and understanding of the embeddedness of knowledge in particular locales. Straddlers need to be chosen with great care as they are key actors in the provision of this education and in the ongoing process of negotiation of embedded knowledge across global locations. They need to have the personal qualities, skills and experience to have empathy, the ability to understand multiple perspectives and be skilled as a communicator. While there is no ready recipe of how such a person can be "constructed," we argue that with more care in 
selection and education, at least some of the problems that Sierra faced could have been reduced.

\subsection{Implications of firm size on managing embedded knowledge}

The analysis of the Sierra case demonstrates the implications of firm size on embedded knowledge. This particular issue has not been previously addressed although Carmel and Nicholson (2005) identity some effects of firm size in global software development. At the same time of studying Sierra, we were also studying similar relationships involving large multinationals, the implications of firm size became evident to us.

Technology firms like Sierra, are what Saxenian (2001) claims are "born global," which are small in size but thrive on their knowledge capital to operate in a global marketplace. Similarly Castells (1996) has argued that firms can succeed in the global domain by leveraging on their intellectual capacity, and that the logic of informational capitalism can allow for the "power of flows to dominate the flows of powers." The implication of Castells' statement is that power is not tied to historically strong institutions like multinational corporations (flows of power) and they can be dominated by the knowledge capital (of even small firms) through their "power of flows" (networking). Our case analysis, challenges this perspective, and emphasises that "size still matters." Sierra was not able to create the conditions within which the organising principles around project management and creativity could be effectively migrated from England to India. Many large firms in India run successful operations, for instance firms like GlobTel (Sahay et al., 2003) have shown that some of the challenges of embedded knowledge experienced by Sierra can be overcome. Such firms have resources to make large scale investments in moving large numbers of expatriates to their India centres and install dedicated high bandwidth telecommunication links. Agents are employed to pay bills, etc. for employees and such companies wield political influence to obtain governmental clearances despite a regulated environment. Resources are available for long-term investments in specific education and training programmes. Also the assumptions that Indian developers lack creativity are strongly challenged when seen against the experiences of other large firms such as SAP and Intel (Economist, 2004). In another case (Sahay et al., 2003), a large Indian software house operating in Japan had the resources to employ several Japanese Anthropology Professors to educate the Indian developers on Japanese culture and language over a 1 year period. When Intel moved operations to Costa Rica, the President intervened personally and cleared bureaucratic pathways. Sierra management were disappointed by their inability to achieve the same results as these firms that they thought they could emulate. Sierra were unable to employ Indian developers who would mirror the Sierra England individualist, "rule breaker" development staff operating in a risk taking environment. Given the constraints of resources and size, a more realistic perspective on the capability of the India centre for innovation and creativity may have led to adoption of more standardised templates. Making large firm investments or wielding political influence is inconceivable for a small 80 person firm like Sierra. Similarly, Sierra could not fight the compe- 
tition of the multinational corporations to recruit high quality graduates from universities like the Indian Institute of Technology. Finally, with limited budgets, small firms like Sierra at the time could not afford to locate on the prestigious technology parks and have a high proportion of expatriate presence in India which is a strategy often adopted by larger firms to reduce some of the challenges in managing the relationship.

However, we would argue that small size is not fatal, and there are many examples of successful small high-tech firms with operations in India. Various strategies could be considered in dealing with the size issue such as creating joint ventures with Indian firms. The cost of locating on technology parks such as Hitec City in Hyderabad is now within the grasp of some small firms offering reliable infrastructure, telecommunications and power supply. Similarly, at the time of writing there are many "broker" organisations, networking institutions such as Indus Entrepreneur and myriad consultants that provide specialised knowledge of how to do outsourcing in particular countries. Services which are becoming standardised and thus reduced in price range from dealing with legal ramifications, providing information on potential partners, helping incubate new relationships and subsidiaries, training and even supporting project management on a long-term basis. Sierra management at the time could have tried to establish such local networks to help develop better understanding of knowledge embedded in Indian societal structures and institutions and also to mitigate some of the constraints of small size and limited capital.

\section{Conclusions}

While the empirical component of this paper was conducted prior to 2000, the conclusions drawn from the Sierra experience have significant implications for contemporary outsourcing debates. One perspective on the debate is that outsourcing is an inevitable necessity in the contemporary global scenario, and for firms to survive, they need to develop software and provide IT enabled services more cost effectively. Outsourcing, which relies on access to cheap labour in developing countries, is seen as a mechanism to provide these efficient services. As a result, offshoring of various categories of work is described by some commentators as being unstoppable. The other on the debate perspective on the debate is that outsourcing leads to a loss of jobs in the host country by relocating them to cheaper sites, and is detrimental to the economy.

In the midst of passionate utopian and dystopian debates over offshore outsourcing and its significant political implications this case provides some empirical substance to the issues being discussed. This case emphasizes the need to consider the challenges of managing the relationship growth over time and that the benefits from outsourcing should not only be seen with respect to salary differences of computer staff, for example in North America and India. To make these relationships work effectively in practice there are many additional costs that need to be taken into the cost equation. Bringing intangible costs into the equation can potentially provide new perspectives and insights on the outsourcing debate. The case emphasizes that 
outsourcing is not merely about managing the economics, but also developing cultural sensitivity and empathy. An imperialist perspective of "creating a little bit of England in India" was ineffective as there was little effort to learn from each other and respect for what the other culture has to provide.

Offshore outsourcing of various categories involves the interaction between different cultures. The authors have had experience over the last few years with software industries in countries as diverse as Argentina, Romania, Russia, Iran and Costa Rica who are keen to engage in offshore outsourcing activity and this provides the vehicle through which cultural understanding can be enhanced. In a contemporary world driven by fear of attacks by "other cultures" there is increasing need and opportunity for such engagement and learning.

\section{Acknowledgements}

Thanks to Geoff Walsham for comments on an earlier draft. We are especially grateful for helpful suggestions and comments made by three anonymous reviewers and associate editor which contributed significantly to the evolution of this paper.

\section{References}

Appadurai, A. (1996). Modernity at large: Cultural dimensions of globalization. Minneapolis: University of Minnesota Press.

Apte, U. (1990). Global outsourcing of information systems and processing services. The Information Society, 7, 287-303.

Avgerou, A. (2002). Information systems and global diversity. Oxford: Oxford University Press.

Arora, A., Arunachalam, V., Asundi, J., \& Fernandes, R. (2001). The Indian software services industry. Research Policy, 30, 1267-1287.

Badaracco, J. (1991). The knowledge link. Harvard Business School Press.

Bechky, B. (2003). Sharing meaning across occupational communities: the transformation of understanding on a production floor. Organization Science, 14(3), 312-330.

Blackler, F. (1995). Knowledge, knowledge work and organisations: an overview and interpretation. Organization Studies, 16(6), 1047-1075.

Brown, J. S. (1998). Internet technology in support of the concept of communities-of-practice: the case of Xerox. Accounting, Management and Information Technologies, 8, 227-236.

Brown, J. S., \& Duguid, P. (1991). Organisational learning and communities of practice: toward a unified view of working learning and innovation. Organization Science, 2(1), 40-57.

Carmel, E. (1997). American hegemony in packaged software trade and the "culture of software". The Information Society, 13(1), 125-142.

Carmel, E. (1999). Global software teams. New Jersey: Prentice Hall.

Carmel, E., \& Agarwal, A. (2002). The maturation of offshore sourcing of IT work. MISQ Executive, 1(2), 65-77.

Carmel, E., \& Nicholson, B. (2005). Small firms and offshore software outsourcing high transaction costs and their mitigation. Journal of Global Information management (forthcoming).

Castells, M. (1996). The rise of the network society. Oxford: Blackwell Publishers.

Castells, M. (2001). The internet galaxy. Oxford: Oxford University Press.

Cockburn, A. (2002). Agile software development. Boston: Addison Wesley Press. 
Cohen, M., \& Bacdayan, P. (1994). Organizational routines are stored as procedural memory: evidence from a laboratory study. Organization Science, 5, 554-568.

Cramton, C. (2001). The mutual knowledge problem and its consequences for dispersed collaboration. Organization Science, 12(3), 346-371.

Curtis, B., Kransner, H., \& Iscoe, N. (1988). A field study of the software design process for large systems. Communications of the ACM, 31(11), 1268-1287.

Cusumano, M. (1991). Japan's software factories: A challenge to U.S. management. Oxford University Press.

Dacin, M. T., Mark, J., Ventresca, M. J., \& Beal, B. D. (1999). The embeddedness of organisations: dialogue and directions. Journal of Management, 25(3), 317-356.

Economist. (2004). Innovation India. April 3 pp. 67-68.

Giddens, A. (1990). Consequences of modernity. Cambridge: Polity.

Granovetter, M. (1985). Economic action and social structure: the problem of embeddedness. American Journal of Sociology, 91(3), 481-510.

Hassard, J. (1999). Images of time in work and organization. In S. R. Clegg \& C. Hardy (Eds.), Studying organization: Theory and method (pp. 327-344). London: Sage Publications.

Hayes, N., \& Walsham, G. (2001). Participation in groupware mediated communities of practice: a socio political analysis of knowledge working. Information and Organization, 11, 263-288.

Herbsleb, J., \& Grinter, R. (1999). Architectures, co-ordination and distance: Conway's law and beyond. IEEE Software, 16(5), 63-70.

Hislop, D. (2002). Mission impossible? Communication and sharing knowledge via information technology. Journal of Information Technology, 17, 165-177.

Huber, G. P. (1991). Organizational learning: the contributing processes and the literatures. Organization Science, 2, 88-115.

Jarvenpaa, S., \& Leidner, D. (1999). Communication and trust in globalvirtual teams. Organization Science, 10(6), 791-815.

Klein, H. K., \& Myers, M. D. (1999). A set of principles for conducting and evaluating interpretive field studies in information systems. MIS Quarterly, 23(1), 67-93.

Kraut, R., \& Streeter, L. (1995). Co-ordination in software development. Communications of the ACM, 38(3), 69-81.

Krishna, S., Sahay, S. (2001). Global software outsourcing experiences in Korea and Japan: Some preliminary investigations. Final Report for the Project The Context of Innovation of the Information Technology Industry, of University of Pennsylvania Institute for the Advanced Study of India, New Delhi, August 2001.

Krishna, S., Sahay, S., Walsham, G. (2003). Managing cross-cultural issues in global software outsourcing. Forthcoming Communications of the ACM.

Lam, A. (1997). Embedded firms, embedded knowledge: problems of collaboration and knowledge transfer in global cooperative ventures. Organization Studies, 18(6), 973-996.

Lam, A. (2000). Tacit knowledge, organisational learning and societal institutions: an integrated framework. Organisational Studies, 21(3), 487-511.

Langley, A. (1999). Strategies for theorising from process data. Academy of Management Review, 24(4), $691-710$.

Lave, J., \& Wenger, E. (1991). Situated learning: Legitimate peripheral participation. New York: Cambridge University Press.

Levitt, B., \& March, J. G. (1988). Organizational learning. Annual Review of Sociology, 14, 319-340.

Mc Dermott, R. (1999). Why information technology inspired but cannot deliver knowledge management. California Management Review, 41(4), 103-117.

McFarlan, F. (1995). Issues in global outsourcing. In P. Palvia, S. Palvia, \& E. Roche (Eds.), Global information technology and systems management: Key issues and trends (pp. 352-364). Nashua: Ivy League Publishing.

Miles, M., \& Huberman, A. (1994). Qualitative data analysis. London: Sage Publications.

Nandhakumar, J. (2002). Managing time in a software factory. The Information Society, 18, $251-262$.

Nicholson, B. (1999). The Process of Software Development Across Time and Space: The Case of Outsourcing to India, Unpublished PhD thesis. Manchester, UK: Salford University. 
Nonaka, I., \& Takeuchi, H. (1994). The knowledge creating company: How Japanese companies create the dynamics of innovation. Oxford: Oxford University Press.

Orr, J. (1990). Sharing knowledge, celebrating identity: community memory in a service culture. In D. Middleton \& D. Edwards (Eds.), Collective remembering (pp. 169-189). London: Sage.

Polanyi, M. (1962). Personal knowledge: Towards a post critical philosophy. New York: Harper Torchbooks.

Polanyi, M. (1966). The tacit dimension. New York: Anchor Day Books.

Robertson, M., Swan, J., \& Scarborough, H. (2000). Creating knowledge within expert consultancy firmsProceedings of the 23rd information systems research seminar in Scandinavia, August, Lingatan (pp. 311-332).

Robey, D., Khoo, S., \& Powers, C. (2000). Situated learning in cross functional virtual teams. IEEE Transactions of Professional Communication, 43, 51-66.

Sahay, S. (1997). Information systems in organisations: a time-space perspective. Organization Studies, $18(2), 229-260$

Sahay, S. (2003). Global software alliances: the challenge of standardization. Scandinavian Journal of Information Systems, 15, 3-22.

Sahay, S., Nicholson, B., \& Krishna, S. (2003). Global IT outsourcing: Micro-studies across borders. Cambridge: Cambridge University Press.

Sahay, S., \& Walsham, G. (1997). Social structure and managerial agency in India. Organization Studies, $18(3), 415-444$

Sarker, S., \& Sahay, S. (2003). Understanding virtual team development: an interpretive study. Journal of the Association of Information Systems, 4, 1-38.

Saxenian, A. (2001). The Silicon Valley connection: Transnational networks and regional development in India, Taiwan and China, Final Report for the project The Context of Innovation of the Information Technology Industry, of University of Pennsylvania Institute for the Advanced Study of India, New Delhi, August 2001.

Singh, S. (2003). A passage of engineering talent back to India. IEEE Spectrum January. 40(1), 22-25.

Sinha, J. B. P. (1984). A model of effective leadership styles. India International Studies of Man and Organisations, 14, 86-98.

Sinha, D., \& Sinha, M. (1990). Dissonance in work culture in India. In A. D. Moddie (Ed.), The concept of work in Indian society (pp. 206-219). New Delhi: Manohar Publications.

Sole, D., \& Edmondson, A. (2002). Situated knowledge and learning in dispersed teams. British Journal of Management, 13, 17-34.

Strauss, A., \& Corbin, J. (1990). Basics of qualitative research: Grounded theory procedures and techniques. London: Sage.

Szulanski, G. (1996). Exploring internal stickiness: impediments to the transfer of best practice within the firm. Strategic Management Journal, 17, 27-43.

Telioglu, H., \& Wagner, I. (1999). Software cultures. Communications of the ACM, 42(12), 71-77.

Tsoukas, H. (1996). The firm as a distributed knowledge system: a constructionist approach. Strategic Management Journal, 17, 11-25.

Uzzi, B. (1996). The sources and consequences of embeddedness for the economic performance of organisations: the network effect. American Sociological Review, 61(4), 674-698.

Vitalari, N. (1985). The need for longitudinal designs in the study of computing environments. In E. Mumford, R. Hirschheim, G. Fitzgerald, \& A. T. Wood Harper (Eds.), Research methods in information systems (pp. 243-262). North Holland: Elsevier Science Publishers.

von Hippel, E. (2001). Sticky information and the locus of problem solving: implications for innovation. Management Science, 40, 429-439.

Walsham, G. (1995). Interpretive case studies in it research: nature and method. European Journal of Information Systems, 4(2), 74-81.

Walsham, G. (2001a). Making a world of difference: IT in a global context. Chichester: Wiley.

Walsham, G. (2001b). Knowledge management: the benefits and limitations of computer systems. European Management Journal, 19(6), 599-608.

Walsham, G. (2002). Cross-cultural software production and use: a structurational analysis. MIS Quarterly, 26(4), 359-380. 
Walsham, G., \& Sahay, S. (1999). GIS technology for district administration in India: some problems and opportunities. MIS Quarterly, 23(1), 39-66.

Walz, D., Elam, J., \& Curtis, B. (1993). Inside a software design team: knowledge acquisition, sharing, and integration. Communications of the ACM, 36(10), 63-77.

Waterson, P., Clegg, C., \& Axtell, C. (1997). The dynamics of work organization, knowledge and technology during software development. International Journal of Human-Computer Studies, 46, 79101.

Zukin, S., \& DiMaggio, P. (1990). Structures of capital: The social organization of the economy. Cambridge: Cambridge University Press. 